\title{
A comparison of different bone graft materials in peri-implant guided bone regeneration
}

\section{Gokhan ARTAS(a) \\ Mehmet GUL(b) \\ Izzet ACIKAN(c) \\ Mustafa KIRTAY(d) \\ Alihan BOZOGLAN(e) \\ Sercan SIMSEK(f) \\ Ferhan YAMAN(g) \\ Serkan DUNDAR(e)}

(a) Firat University, Faculty of Medicine, Department of Medical Pathology, Elazig, Turkey.

(b) Harran University, Faculty of Dentistry, Department of Periodontology, Sanliurfa, Turkey.

(c)Sütcü Imam University, Faculty of Dentistry, Department of Oral and Maxillofacial

Surgery, Kahramanmaras, Turkey.

(d) Private Practice, Oral and Maxillofacial

Surgery, Toronto, Canada

(e) Firat University, Faculty of Dentistry,

Department of Periodontology, Elazig, Turkey

(f) Ministry of Health, Tunceli State Hospital,

Department of Medical Pathology, Tunceli, Turkey

(g) Private Practice, Oral and Maxillofacial

Surgery, Diyarbakir, Turkey.

Declaration of Interests: The authors certify that they have no commercial or associative interest that represents a conflict of interest in connection with the manuscript.

Corresponding Author:

Serkan Dundar

E-mail: dtserkandundar@gmail.com

htrps://doi.org/10.1590/1807-3107bor-2018.vol32.0059

Submitted: January 21, 2018

Accepted for publication: May 02, 2018

Last revision: May 16, 2018
Abstract: The aim of this study was to compare the effects of hydroxyapatite (HA), deproteinized bovine bone (DPB), human-derived allogenic bone (HALG), and calcium sulfate (CAP) graft biomaterials used with titanium barriers for bone augmentation to treat peri-implant defects in rat calvarium treated by guided bone regeneration (GBR). Thirty-two female Sprague-Dawley rats were divided into four groups: DPB, HALG, HA, and CAP. One titanium barrier was fixed to each rat's calvarium after the titanium implants had been fixed. In total, 32 titanium implants and barriers were used. Ninety days after the surgical procedure, all the barriers were removed. After decalcification of bone tissue, the titanium implants were removed gently, and new bone regeneration in the periimplant area was analyzed histologically. Immunohistochemical staining of vascular endothelial growth factor (VEGF) was also performed. There were no statistically significant between-group differences in new bone regeneration or VEGF expression after 3 months. According to the results of the histological and immunohistochemical analyses, none of the grafts used in this study showed superiority with respect to new bone formation.

Keywords: Bone Regeneration; Durapatite; Hydroxyapatites; Calcium Sulfate.

\section{Introduction}

The guided bone regeneration (GBR) method is used for the treatment of peri-implant bone tissue defects in oral-dental implantology. ${ }^{1}$ In GBR, a barrier membrane is used to preserve blood formation and create a closed area around the bone tissue defect. ${ }^{2,3,4}$ The GBR method encourages the proliferation of bone-forming cells called osteoblasts. ${ }^{2,3,4}$ In GBR, the barrier membrane must be permeable to enable the diffusion of nutrients required for bone regeneration. ${ }^{5}$ Previous experimental studies reported more successful bone tissue regeneration using the GBR procedure and a hermetically-closed, stiff occlusive titanium barrier as compared with permeable membranes in a rabbit calvarium model. ${ }^{6,7,8}$

Autogenous bone grafts contain growth factors and promote the recruitment of stem cells. ${ }^{910}$ Due to their osteoinductive and osteoconductive properties, autogenous bone grafts are the current gold standard for bone augmentation procedures. However, autogenous bone grafts of extraoral origin also have a number of disadvantages. These include the need for 
a second surgical procedure; a limited supply of bone grafts; and postsurgery morbidity, pain, and neural damage in the donor bone area, as well as patient discomfort. ${ }^{11,12}$ Thus, various alternative bone graft materials, such as deproteinized bovine bone (DPB), human-derived allogenic bone (HALG), hydroxyapatite (HA), and calcium sulfate (CAP) bioceramic biomaterials, have been developed as alternative graft materials to autologous grafts.,10 Allografts, such as deproteinized human bone grafts, are one of the most commonly-used alternatives to autografts in the treatment of bone tissue defects. However, allografts have various disadvantages, including an increased risk of infections (hepatitis and HIV). Controversy also surrounds their osteoinductive potential. In experimental animal models, researchers reported increased bone regeneration using calcium phosphate ceramic-derived bone graft biomaterials (HA, tricalcium phosphate, and calcium sulfate), in addition to superior stability and osteogenic properties, compared to autologous bone grafts. ${ }^{12}$ In experimental and clinical research, another study demonstrated the osteoconductive capacity of this type of graft material (ceramic-derived bone graft biomaterial) in a GBR procedure for the treatment of bone tissue defects. ${ }^{13}$

The aim of the present study was to compare the effects of HA-, DPB-, HALG-, and CAP-derived bone graft biomaterials used with titanium barriers on bone augmentation in a peri-implant GBR procedure in rat calvarium.

\section{Methodology}

The study consisted of 32 female Sprague-Dawley rats, which were provided by the Experimental Research Center of Firat University. The experimental protocol and procedures in this study were approved by the Animal Experimental Ethics Committee of Firat University (Elazig, Turkey). The welfare and care of the experimental animals complied with the guidelines of the Helsinki Declaration. Throughout the experiment, the rats were kept in standard cages and fed a standard diet, with access to drinking water ad libitum. The 32 rats were divided into four graft groups: HA, DPB, HALG, and CAP.
Rigid dome-shaped titanium barriers with a hole in the top were constructed, and the top was covered with a Teflon ${ }^{\mathrm{TM}}$ cap to produce a hermetic seal. Prior to the surgical procedures, all the titanium barriers were cleaned and sterilized. All the surgical procedures were performed under sterile conditions. General anesthesia was induced with $10 \mathrm{mg} / \mathrm{kg}$ of xylazine and $40 \mathrm{mg} / \mathrm{kg}$ of ketamine. After the induction of general anesthesia and before surgery, the skull skin was shaved, and the skin was washed with povidone iodine. A skin incision was made over the linea media on the skull. To reach the skull bones, the flap and periosteum were lifted using a periosteal elevator. Nine holes were then created using a standard steel burr of $1 \mathrm{~mm}$ diameter, with water irrigation to prevent burning of the bone. After this procedure, an implant cavity $2 \mathrm{~mm}$ long $\times 2 \mathrm{~mm}$ wide was created using a steel burr. Then, $4 \mathrm{~mm}$ long $\times 2 \mathrm{~mm}$ wide titanium implants with a machined surface were placed in the center of the grafted area. The titanium barriers were placed around the implants and holes. The edges of the titanium barriers were fixed to the skull bone tissue using the adhesive N-butyl-2-cyanoacrylate.

After these procedures, the grafts were embedded in the holes in the titanium barriers, and the holes were then covered with Teflon ${ }^{\mathrm{TM}}$ caps. The skull skin and soft tissue were sutured using resorbable sutures. An antibiotic and analgesic were injected intramuscularly in all animals once a day for the first three postoperative days. After 3 months, all the rats were sacrificed by carbon dioxide inhalation. Following sacrifice, the titanium barriers were removed, and the calvarial bones containing the implants were harvested for histomorphometric and immunohistochemical analyses.

The original grafted bone tissue was used for histomorphometric and immunohistochemical analyses. The bone tissue samples were fixed in $10 \%$ formaldehyde solution for $72 \mathrm{~h}$ and demineralized in $10 \%$ formic acid solution. The implants were then gently removed from the samples. After decalcification, bone tissue samples were dehydrated, embedded in a paraffin wax block, and sectioned for hematoxylin and eosin (HE) and Masson's trichrome (MT) staining and microscopic analyses. 
Sections $6 \mu \mathrm{m}$ thick corresponding to the bone augmentation area were evaluated via light microscopy. New bone formation was determined by calculating the amount of regenerated new bone area as a percentage of the total grafted area in the peri-implant bone tissues using an image analysis program. All images of histological samples were taken with a digital camera attached to a light microscope, and the images were transferred to a computer at the original magnification. ${ }^{14}$ An Olympus DP71 (Tokyo, Japan) software imaging system was used for histomorphometric analysis.

The bone specimens were fixed by perfusion, decalcified, and embedded in paraffin as previously described. The sections were incubated for 10 $\min$ in an oven at $60^{\circ} \mathrm{C}$, and then cut into $4 \mu \mathrm{m}$ longitudinal sections. The sections were then transferred to an automatic staining machine for VEGF immunohistochemical staining. After the primary antibody procedure, the sections were washed with water and stored in ultramount.

In the immunohistochemical analysis, the staining ratio (\%) of VEGF in regenerated new bone areas was calculated using an image analysis program. ${ }^{14}$ All the images of histological samples were taken with a digital camera attached to a light microscope and transferred to a computer at the original magnification. An Olympus DP71 software imaging system was used for immunohistochemical analysis.

\section{Statistical analysis}

SPSS 22 software was used for statistical analysis. The data were analyzed using one-way ANOVA and Tukey's HSD tests. A value of $p<0.05$ was accepted as denoting a statistically significant difference.

\section{Results}

No fatal or nonfatal complications (such as wound infection) were encountered during the experiment.

New bone formation ratios were $45.38 \pm 4.24 \%$, $43.63 \pm 6.30 \%, 45.25 \pm 6.71 \%$ and $42.75 \pm 5.7 \%$ in the HA, DPB, HALG and CAP groups, respectively. There was no statistically significant difference between the four groups (one way ANOVA, p > 0.05) (Table, Figures 1 and 2).
VEGF immunohistochemical staining ratios were $40.75 \pm 3.96,41 \pm 3.46 \%, 36.75 \pm 4.27 \%$ and $38.38 \pm 4.21 \%$ in the HA, DPB, HALG and CAP groups, respectively, and no statistically significant difference was found between the four groups (one way ANOVA, $p>0.05$ ) (Table 1, Figures 2 and 3).

No evidence of inflammatory activity was detected microscopically.

\section{Discussion}

The bone formation capacity of bone graft materials differed widely, and bone regeneration capacity influenced the integration of implanted bone grafts. ${ }^{8,9,10}$ Although much progress has been made in recent years in oral implantology, autogenous bone grafts remain the gold standard in GBR procedures. ${ }^{8,10,11}$ They have a major advantage in that they supply not only bone volume but also osteogenic cells, which are capable of quickly laying down new bone. However, they also have various drawbacks, including increased patient morbidity, limited bone graft availability, and additional surgical time/costs. . $^{8,910,11}$ Thus, studies aimed at identifying substitutes have been conducted.

Previous studies of an experimental animal bone defect grafting model reported that 3 months was a sufficient time to induce healing and the emergence of angiogenesis and new bone formation., ${ }^{9,10,15}$ In the present study, we observed marked histological changes in the grafted bone defects 3 months after the grafting procedure in all four groups.

Table. New bone formation (NBF) and vascular endothelial growth factor (VEGF) percentage of the groups (one way ANOVA, $\mathrm{p}>0.05$ ).

\begin{tabular}{lccccc}
\hline Parameters & Groups & $\mathrm{n}$ & Mean(\%) & $\begin{array}{c}\text { Standart } \\
\text { deviation }\end{array}$ & $\mathrm{p}$ \\
\hline \multirow{4}{*}{ NBF } & HA & 8 & 45.38 & 4.24 & \\
& DPB & 8 & 43.63 & 6.30 & \\
& HALG & 8 & 45.25 & 6.71 & 0.764 \\
\multirow{4}{*}{ VEGF } & CAP & 8 & 42.75 & 5.73 & \\
& HA & 8 & 40.75 & 3.96 & \\
& DPB & 8 & 41 & 3.46 & \\
& HALG & 8 & 36.75 & 4.27 & 0.127 \\
\hline
\end{tabular}



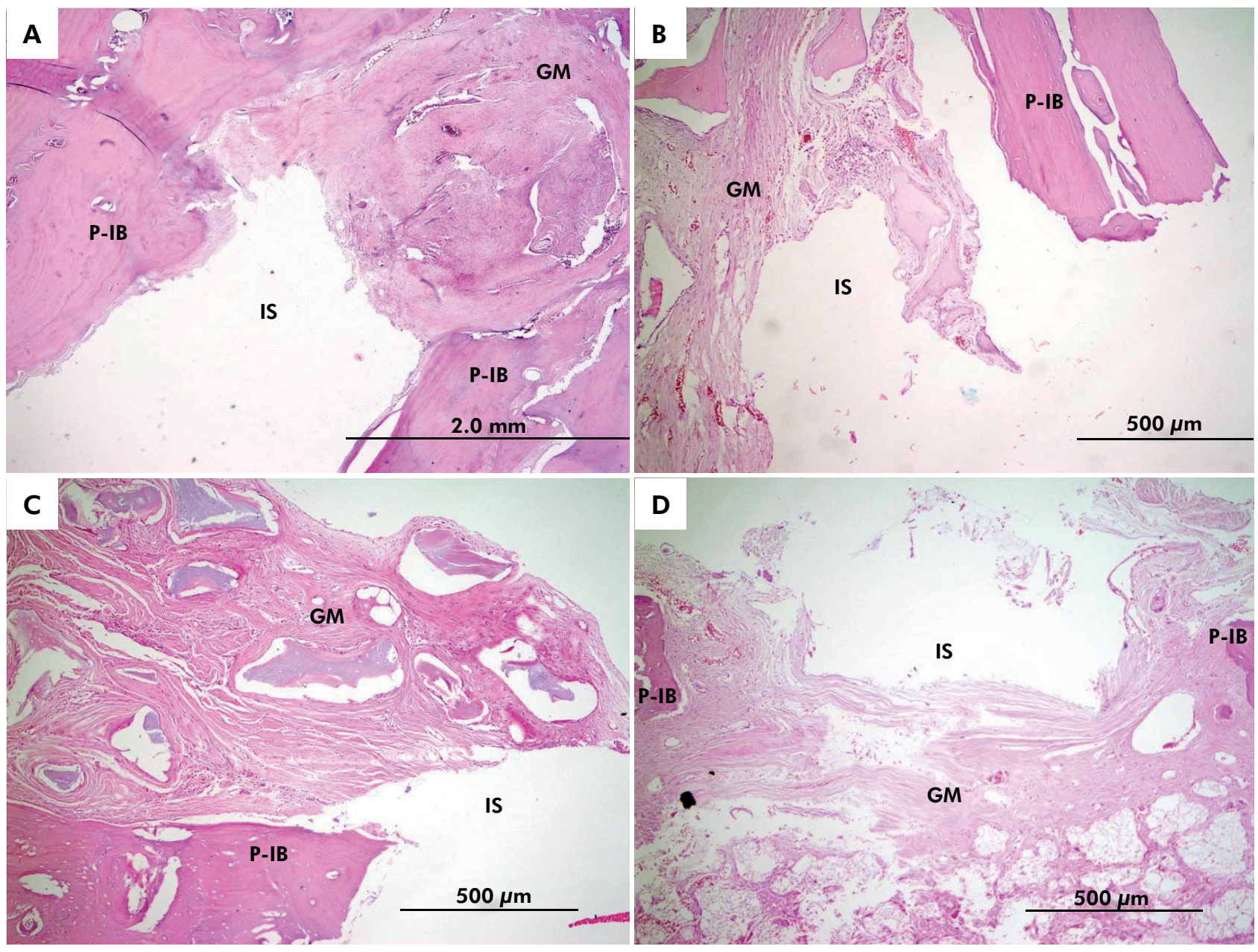

Figure 1. Histological images of a) calcium sulfate, b) deproteinized bovine, c) human-derived allogenic, and d) hydroxyapatite bone grafts. Hematoxylin and eosin staining.

The findings of the present study showed that bone formation beyond the skeletal system should occur in a similar way to that observed in previous studies. In an experimental animal study, Manfro et al. ${ }^{16}$ and Maréchal et al. ${ }^{17}$ reported that new bone regeneration beyond the normal anatomic limits of a rabbit's skull bone occurred with autogenous blood application. Min et al. ${ }^{7}$ demonstrated that new bone regeneration occurred after decortication of calvarial bone. In another experimental study, Ezirganli et al. ${ }^{9}$ reported that new bone formation took place with different bone grafts and decortication of the calvarium.

The most common grafts used today are autografts, allografts, demineralized bone matrix, xenograft (bovine), and substitute bone grafts (calcium sulfate, calcium phosphate and $\mathrm{HA}) .{ }^{17}$ To determine which graft is most appropriate for a given condition, an understanding of the biological function (osteogenesis, osteoinduction, and osteoconduction) of each graft is necessary. Furthermore, stable conditions in the host are essential for the incorporation of any graft material. Despite their drawbacks, autogenous bone autografts remain the gold standard to which every substitute must be compared.

The results of the present study were in accordance with those of previous studies of experimental applications of xenografts, human allografts, HA, and calcium sulfate grafts. There are a few reports in the literature on xenograft bone substitutes. Some studies showed good results in animal models and clinical research, whereas others demonstrated slower integration using xenograft bone substitutes compared with human allografts or lower bone union 



Figure 2. Histological images of a) calcium sulfate, b) deproteinized bovine, c) human-derived allogenic, and d) hydroxyapatite bone grafts. Masson's trichrome staining.

rates, with persistent radiolucent lines and local complications. ${ }^{17,18,19}$ Calcium sulfate has been used many times as a bone void filler. ${ }^{18,19}$ Recently, surgical grade calcium sulfate has been employed as a bone graft substitute. ${ }^{17,18,19,20}$ Multicenter clinical studies demonstrated that trabecular bone filling in autografts was qualitatively similar to that seen in calcium sulfate grafts. $17,18,19,20,21$ They also showed that surgical grade calcium sulfate was a host friendly and environmentally friendly biomaterial, which induced satisfactory bone production. ${ }^{1718,19,20}$ Researchers also demonstrated that the histological grade score for calcium sulfate was similar to that of other graft substitutes. $17,18,19,20,21$

Alloplastic bone graft materials should be biocompatible and not antigenic or trigger the inflammatory process. ${ }^{20,22,23,24} \mathrm{~A}$ previous study revealed that HA-derived synthetic bone grafts stimulated new bone tissue formation and had high osteogenic potential. ${ }^{21}$ HA-derived synthetic bone grafts, when compared with autogenous bone, were shown to encourage new bone formation in experimental animal studies, with excellent stability and new bone regenerative properties. Due to their content and structure, HA bone grafts dissolved slowly and were displaced gradually by bone tissue. ${ }^{18}$

Demineralized human bone allografts are thought to have osteoinductive capabilities and fast resorption, with bone ingrowth. ${ }^{17}$ Demineralized freeze-dried bone allografts are extensively utilized in regenerative oral implantology, as they possess excellent osteoconductive potential. ${ }^{25,26,27}$

Angiogenesis is the mostimportant pathophysiological process in bone repair and formation. VEGF has 

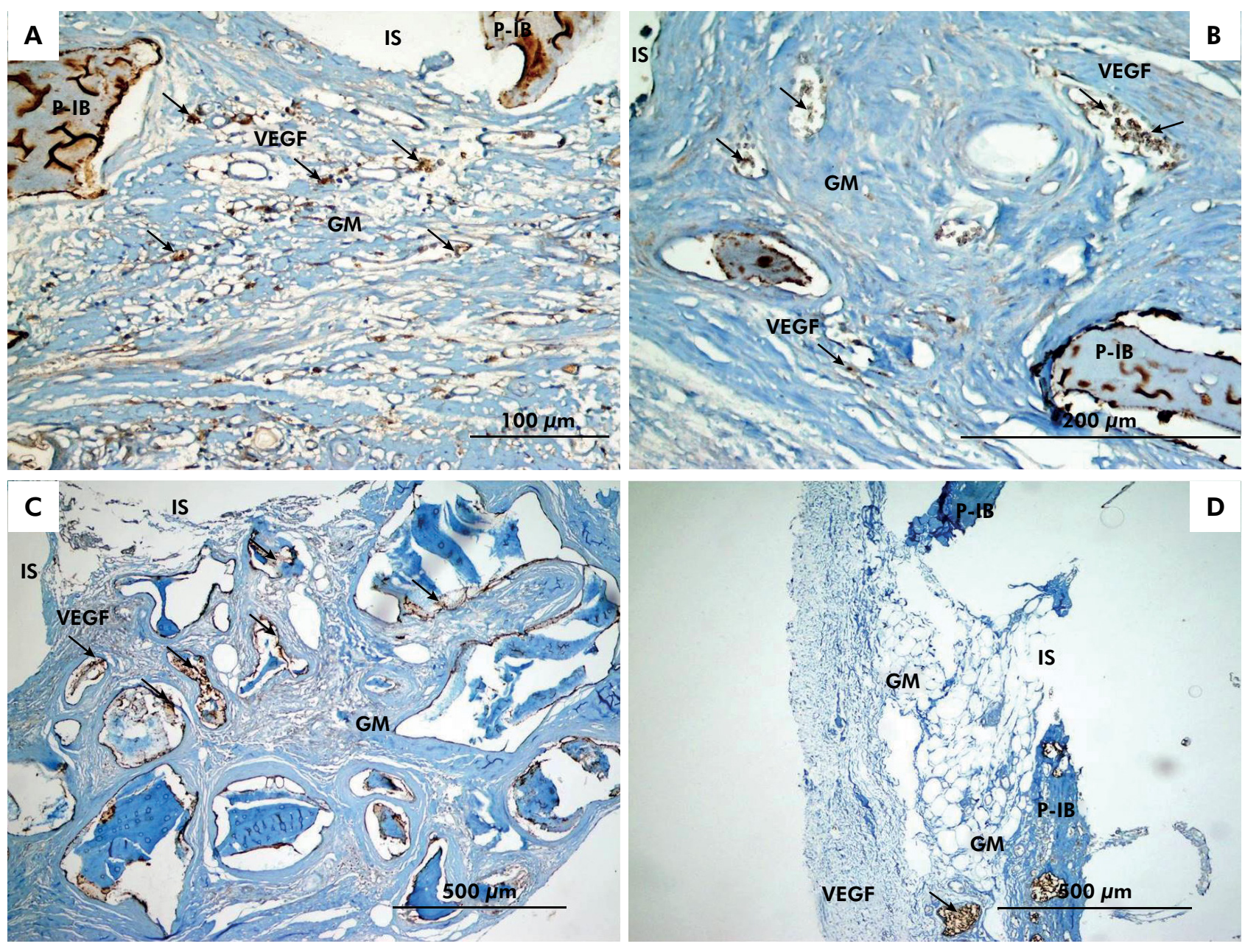

Figure 3. Immunohistochemical staining of VEGF in the a) calcium sulfate, b) deproteinized bovine, c) human-derived allogenic, and d) hydroxyapatite bone graft groups.

an important role in angiogenesis and induces angiopoiesis over vascular endothelial cells. VEGF, which is expressed by endothelial cells, is one of the most important cytokines in angiogenesis and is associated with bone formation, mesenchymal condensation, cartilage formation, cartilage resorption, and blood vessel invasion. ${ }^{28}$ In immunohistochemical examination, VEGF expression was detected in all groups at similar levels with no significant difference between the groups.

In the present study, new bone tissue regeneration was evident in all the groups three months after implantation, with no statistically significant betweengroup differences. The histological findings indicated that all four graft materials (HA, DPB, HALG, and $\mathrm{CAP}$ ) exhibited osteoconductive properties.

\section{Conclusion}

The present study compared the histological properties of several bone graft substitutes, which are widely utilized today. According to the results, none of the grafts showed superiority with respect to new bone formation. Although a number of studies in the field of oral implantology have examined the effects of different graft materials on peri-implant bone repair and regeneration, it is still unclear how these graft materials work or under which conditions they should be used. ${ }^{3-5,13}$ Additional studies are needed to define the indications, specifications, limitations, and contraindications of GBR in the treatment of peri-implant bone defects. 


\section{References}

1. Schwarz F, Herten M, Ferrari D, Wieland M, Schmitz L, Engelhardt $E$ et al. Guided bone regeneration at dehiscencetype defects using biphasic hydroxyapatite + beta tricalcium phosphate (Bone Ceramic) or a collagen-coated natural bone mineral (BioOss Collagen): an immunohistochemical study in dogs. Int J Oral Maxillofac Surg. 2007 Dec;36(12):1198-206. https://doi.org/10.1016/j.ijom.2007.07.014

2. Dahlin C, Linde A, Gottlow J, Nyman S. Healing of bone defects by guided tissue regeneration. Plast Reconstr Surg. 1988 May;81(5):672-6. https://doi.org/10.1097/00006534-198805000-00004

3. Chiapasco M, Zaniboni M. Clinical outcomes of GBR procedures to correct peri-implant dehiscences and fenestrations: a systematic review. Clin Oral Implants Res. 2009 Sep;20 Suppl 4:113-23. https://doi.org/10.1111/j.1600-0501.2009.01781.x

4. Hämmerle $\mathrm{CH}$, Lang NP. Single stage surgery combining transmucosal implant placement with guided bone regeneration and bioresorbable materials. Clin Oral Implants Res. 2001 Feb;12(1):9-18. https://doi.org/10.1034/i.1600-0501.2001.012001009.x

5. Ezirganlı Ş, Polat S, Barış E, Tatar I, Çelik HH. Comparative investigation of the effects of different materials used with a titanium barrier on new bone formation. Clin Oral Implants Res. 2013 Mar;24(3):312-9. https://doi.org/10.1111/j.1600-0501.2011.02323.x

6. Schmid J, Hämmerle CH, Olah AJ, Lang NP. Membrane permeability is unnecessary for guided generation of new bone: an experimental study in the rabbit. Clin Oral Implants Res. 1994 Sep;5(3):125-30. https://doi.org/10.1034/j.16000501.1994.050302.x PMID:7827226

7. Min S, Sato S, Saito M, Ebihara H, Arai Y, Ito K. Microcomputerized tomography analysis: dynamics of bone augmentation within a titanium cap in rabbit calvarium. Oral Surgery, Oral Medicine, Oral Pathology, Oral Radiology, and Endodontics 2008;106(6):892-5. https://doi.org/10.1016/i.tripleo.2008.04.012

8. Molly L, Quirynen M, Michiels K, Steenberghe D. Comparison between jaw bone augmentation by means of a stiff occlusive titanium membrane or an autologous hip graft: a retrospective clinical assessment. Clin Oral Implants Res. 2006 Oct;17(5):4817. https://doi.org/10.1111/j.1600-0501.2006.01286.x

9. Ezirganli S, Kazancioglu HO, Mihmanli A, Sharifov R, Aydin MS. Comparative investigation of the effects of different materials used with a titanium barrier on new bone formation. Clin Oral Implants Res. 2015 Dec;26(12):1482-8. https://doi.org/ 10.1111/clr.12495.

10. Ocak H, Kutuk N, Demetoglu U, Balcıoglu E, Ozdamar $\mathrm{S}$, Alkan A. Comparison of bovine bone-autogenic bone mixture versus platelet-rich fibrin for maxillary sinus grafting: histologic and histomorphologic study. J Oral Implantol. 2017 Jun;43(3):194-201. https://doi.org/10.1563/aaid-joi-D-16-00104
11. Ezirganlı Ş, Kazancıoğlu HO, Mihmanlı A, Aydın MŞ, Sharifov $R$, Alkan A. The effect of local simvastatin application on critical size defects in the diabetic rats. Clin Oral Implants Res. 2014 Aug;25(8):969-76. https://doi.org/10.1111/clr.12177

12. Alam S, Ueki K, Nakagawa K, Marukawa K, Hashiba Y, Yamamoto $E$ et al. Statin-induced bone morphogenetic protein (BMP) 2 expression during bone regeneration: an immunohistochemical study. Oral Surg Oral Med Oral Pathol Oral Radiol Endod. 2009 Jan;107(1):22-9. https://doi.org/10.1016/j.tripleo.2008.06.025

13. Ozdemir H, Ezirganli S, Isa Kara M, Mihmanli A, Baris E. Effects of platelet rich fibrin alone used with rigid titanium barrier. Arch Oral Biol. 2013 May;58(5):537-44. https://doi.org/10.1016/i.archoralbio.2012.09.018

14. Raposo-Ferreira TM, Salvador RC, Terra EM, Ferreira $\mathrm{JH}$, Vechetti-Junior IJ, Tinucci-Costa M et al. Evaluation of vascular endothelial growth factor gene and protein expression in canine metastatic mammary carcinomas. Microsc Res Tech. 2016 Nov;79(11):1097-104. https://doi.org/10.1002/jemt.22763

15. Dundar S, Artas G, Acikan I, Yaman F, Kirtay M, Ozupek MF et al. Comparison of the effects of local and systemic zoledronic acid application on mandibular distraction osteogenesis. J Craniofac Surg. 2017 Oct;28(7):e621-5. https://doi.org/10.1097/SCS.0000000000003629

16. Manfro R, Fonseca FS, Bortoluzzi MC, Sendyk WR. Comparative, histological and histomorphometric analysis of three anorganic bovine xenogenous bone substitutes: Bio-oss, bone-fill and gen-ox anorganic. J Maxillofac Oral Surg. 2014 Dec;13(4):464-70. https://doi.org/10.1007/s12663-013-0554-z

17. Maréchal M, Luyten F, Nijs J, Postnov A, Schepers E, Steenberghe D. Histomorphometry and micro-computed tomography of bone augmentation under a titanium membrane. Clin Oral Implants Res. 2005 Dec;16(6):708-14. https://doi.org/10.1111/j.1600-0501.2005.01205.x

18. Miron RJ, Zhang Q, Sculean A, Buser D, Pippenger BE, Dard $M$ et al. Osteoinductive potential of 4 commonly employed bone grafts. Clin Oral Investig. 2016 Nov;20(8):2259-65. https://doi.org/10.1007/s00784-016-1724-4

19. Kelly CM, Wilkins RM, Gitelis S, Hartien C, Watson JT, Kim PT. The use of a surgical grade calcium sulfate as a bone graft substitute: results of a multicenter trial. Clin Orthop Relat Res. 2001 Jan;382:42-50. https://doi.org/10.1097/00003086-200101000-00008

20. Walsh WR, Morberg P, Yu Y, Yang JL, Haggard W, Sheath PC et al. Response of a calcium sulfate bone graft substitute in a confined cancellous defect. Clin Orthop Relat Res. 2003 Jan;406(406):228-36. https://doi.org/10.1097/00003086-200301000-00033 
A comparison of different bone graft materials in peri-implant guided bone regeneration

21. Broggini N, Bosshardt DD, Jensen SS, Bornstein MM, Wang CC, Buser D. Bone healing around nanocrystalline hydroxyapatite, deproteinized bovine bone mineral, biphasic calcium phosphate, and autogenous bone in mandibular bone defects. J Biomed Mater Res B Appl Biomater. 2015 Oct;103(7):1478-87. https://doi.org/10.1002/jbm.b.33319

22. Yuan H, Fernandes $H$, Habibovic P, Boer J, Barradas AM, Ruiter $\mathrm{A}$ et al. Osteoinductive ceramics as a synthetic alternative to autologous bone grafting. Proc Natl Acad Sci USA. 2010 Aug;107(31):13614-9. https://doi.org/10.1073/pnas.1003600107

23. Chan O, Coathup MJ, Nesbitt A, Ho CY, Hing KA, Buckland T et al. The effects of microporosity on osteoinduction of calcium phosphate bone graft substitute biomaterials. Acta Biomater. 2012 Jul;8(7):2788-94. https://doi.org/10.1016/j.actbio.2012.03.038

24. Coathup MJ, Hing KA, Samizadeh S, Chan O, Fang YS, Campion C et al. Effect of increased strut porosity of calcium phosphate bone graft substitute biomaterials on osteoinduction. J Biomed Mater Res A. 2012 Jun;100(6):1550-5. https://doi.org/10.1002/ibm.a.34094
25. Habibovic P, Gbureck U, Doillon CJ, Bassett DC, Blitterswijk CA, Barralet JE. Osteoconduction and osteoinduction of low-temperature 3D printed bioceramic implants. Biomaterials. 2008 Mar;29(7):944-53. https://doi.org/10.1016/i.biomaterials.2007.10.023

26. Wei L, Miron RJ, Shi B, Zhang Y. Osteoinductive and osteopromotive variability among different demineralized bone allografts. Clin Implant Dent Relat Res. 2015 Jun;17(3):533-42. https://doi.org/10.1111/cid.12118

27. Schwartz Z, Somers A, Mellonig JT, Carnes DL Jr, Dean DD, Cochran DL et al. Ability of commercial demineralized freeze-dried bone allograft to induce new bone formation is dependent on donor age but not gender. J Periodontol. 1998 Apr;69(4):470-8. https://doi.org/10.1902/jop.1998.69.4.470

28. Liao H, Zhong Z, Liu Z, Li L, Ling Z, Zou X. Bone mesenchymal stem cells co-expressing VEGF and BMP- 6 genes to combat avascular necrosis of the femoral head. Exp Ther Med. 2018 Jan;15(1):954-62. https://doi.org/10.3892/etm.2017.5455 